\title{
Increased concentrations of D-dimers in newborn infants
}

\author{
I R B Hudson, B E S Gibson, J Brownlie, B M Holland, T L Turner, R G Webber
}

\begin{abstract}
The concentrations of D-dimers (the D fragments of fibrinogen) were measured in blood from 15 preterm infants, and 45 born at full term, to establish normal ranges. The adult normal range is $<0.25 \mathrm{mg} / 1 ; 31$ of the 60 infants $(52 \%)$ had values $<0.25 \mathrm{mg} / 1$, in 16 $(27 \%)$ they were $0.25-0.5$, in eight $(13 \%)$ $0.5-1$, in three (5\%) $1-2$, and in two (3\%) $2-4$.

D-dimer concentrations measured during the neonatal period should be interpreted with caution.
\end{abstract}

D-dimers (D fragments of fibrinogen) are produced during plasmin mediated lysis of fibrin. ${ }^{1}$ They are more specific than fibrin/fibrinogen degradation products, which are formed during degradation of fibrinogen and fibrin. ${ }^{2} \mathrm{D}$-dimers can be measured using $10 \mu \mathrm{l}$ of plasma in five minutes from specimens taken in EDTA, heparin, or citrate by a latex agglutination technique. $^{3}$

In adults the concentration of D-dimers is the most sensitive marker for monitoring the activity of disseminated intravascular coagulation, ${ }^{3}$ and the adult normal range is less than $0.25 \mathrm{mg} / \mathrm{l}^{4}$ The aim of this study was to evaluate the test in newborn infants and to find out whether pregnant women had significantly increased values before delivery that might affect the concentrations in their infants.

\section{Patients and methods}

Full blood counts, coagulation screens, and D-dimers were measured in samples of venous blood taken from 15 preterm infants and 45 born at full term. The gestational ages of the preterm infants were: $27-28$ weeks $(n=1)$, 29-30 weeks $(n=1), 31-32$ weeks $(n=10)$, and 33-34 weeks $(n=3)$. The preterm infants had no serious complications of prematurity, although two received short periods of ventilation (less than 24 hours); this is our routine for infants of less than 30 weeks' gestational age. All infants received vitamin $K 1 \mathrm{mg}$ at birth by intramuscular injection.

For ethical reasons, only those infants born at full term who required blood sampling for other investigations (predominantly jaundice) had coagulation screens carried out. The indication for blood sampling was usually non-haemolytic jaundice $(n=27)$; other indications included growth retardation $(n=6)$, vomiting $(n=4)$, passing maternal blood $(n=3)$, 'spots' $(n=3)$, and diabetes in the mother $(n=2)$. Eighteen of the jaundiced infants required phototherapy; all other conditions resolved spontaneously. No infant had a positive blood culture and all were being fed enterally with either breast milk or formula milk. Blood sampling was carried out either on admission to the nursery (preterm infants) or between the first and the fifth day (infants born at full term).

\section{MATERNAL SAMPLES}

D-dimers were measured in 17 randomly selected pregnant women at full term who were in early uncomplicated labour.

\section{LABORATORY METHODS}

Full blood counts were measured using a Coulter s880 cell counter. Plasma from citrated blood specimens was assayed for D-dimers by a semiquantative latex agglutination test with a monoclonal antibody (Dimertest Latex, Agen Biomedical Ltd). ${ }^{3}$

Activated partial thromboplastin time was measured with Actin FS reagent (Dade, American Hospital Supply), and the normal adult range is $24-40$ seconds. Prothrombin time was measured with rabbit brain thromboplastin (Manchester Thrombosis Research Foundation), and the normal adult range is 14-18 seconds. Thrombin calcium time was measured with bovine thrombin (Dade, American Hospital Supply), and the normal adult range is 9-13 seconds. Fibrinogen was measured by the Clauss thrombin clottable protein method, and the normal adult range is $1.5-4.0 \mathrm{~g} / \mathrm{l}$.

\section{Results}

The results of coagulation screening tests in the infants born at full term are shown in table 1 , and the results of the D-dimers estimations are shown in table 2 . All the infants had normal platelet counts $\left(150-400 \times 10^{9} / 1\right)$.

No association was found between the D-dimers concentration and the indication for blood sampling, the age of the infant at the time of sampling, the type of feeding, or whether the infant received phototherapy.

Table 1 Results of coagulation screening tests in 45 infants born at full term

\begin{tabular}{llc}
\hline & Mean $(S D)$ & Range \\
\hline Prothrombin time (secs) & $16(1 \cdot 7)$ & $13-20$ \\
Activated partial thromboplastin & $32 \cdot 8(5 \cdot 1)$ & $22-45$ \\
time (secs) & $11 \cdot 1(1 \cdot 2)$ & $9-13$ \\
Thrombin calcium time (secs) & $2 \cdot 8(0 \cdot 7)$ & $1 \cdot 6-4 \cdot 2$ \\
Fibrinogen (g/l) & \\
\hline
\end{tabular}


Table 2 Concentrations of D-dimers in blood from 15 preterm infants and 45 born at full term

\begin{tabular}{|c|c|c|c|}
\hline \multirow{2}{*}{$\begin{array}{l}\text { Concentrations of } \\
\text { D-dimers }(\mathrm{mg} / \mathrm{l})\end{array}$} & \multicolumn{3}{|c|}{ No (\%) of infants } \\
\hline & $\begin{array}{l}\text { Born at } \\
\text { full term } \\
(n=45)\end{array}$ & $\begin{array}{l}\text { Born } \\
\text { preterm } \\
(n=15)\end{array}$ & $\begin{array}{l}\text { Total } \\
(n=60)\end{array}$ \\
\hline $\begin{array}{l}<0 \cdot 25 \\
0 \cdot 25-0 \cdot 5 \\
0 \cdot 5-1 \\
1-2 \\
2-4\end{array}$ & $\begin{aligned} 24 & (53) \\
14 & (31) \\
6 & (13) \\
1 & (2) \\
0 & \end{aligned}$ & $\begin{array}{l}7(47) \\
2(13) \\
2(13) \\
2(13) \\
2(13)\end{array}$ & $\begin{array}{c}31(52) \\
16(27) \\
8(13) \\
3(5) \\
2(3)\end{array}$ \\
\hline
\end{tabular}

All D-dimers concentrations in the pregnant mothers were $<0.25 \mathrm{mg} / \mathrm{l}$.

\section{Discussion}

Measurement of D-dimers concentrations has been suggested as an alternative to measuring fibrin/fibrinogen degradation products, as they have been shown to be more sensitive. and specific and can be measured in as little as $10 \mu \mathrm{l}$ of plasma. Normal adults have plasma concentrations of $<0.25 \mathrm{mg} / \mathrm{l}$. Using the more sensitive ELISA antibody test, mildly increased concentrations have also been found in normal pregnant women. ${ }^{5}$ We were unable to confirm this finding in women in labour in whom D-dimers were measured by the latex agglutination technique.

The results of measurements of D-dimers in infants show that the range of plasma concentrations found in normal adults does not apply either to preterm infants or to those born at full term, as about half the infants had values outside the accepted adult range.

The reason for the increased concentrations of D-dimers in these infants is unknown. Trans- placental passage is unlikely, because the concentrations found in 17 pregnant mothers before delivery were all less than $0.25 \mathrm{mg} / \mathrm{l}$. Other possible explanations are that D-dimers may represent low grade activation of the coagulation system as a result of the circulatory adjustments of closure of the ductus venosus and ductus arteriosus after birth, or perhaps there is delayed renal clearance of D-dimers in the newborn. Fibrin/fibrinogen degradation products have also been found in $65 \%$ of normal term infants. ${ }^{6}$ The results of coagulation screening tests in infants born at full term were similar to those in normal adults.

We conclude that newborn infants have ranges of concentrations for D-dimers that are different from adults, and therefore caution is necessary in their use and interpretation.

I R B Hudson is supported by a grant from the Scottish Hospitals Endowment Research Trust. We thank the technical staff of the haematology department for their help in analysing the specimens and Miss $\mathrm{K}$ Black for typing the manuscript.

1 Lane DA, Preston FE, VanRoss ME, Kakkar VV. Characterisation of serum fibrinogen and fibrin fragments produced during disseminated intravascular coagulation. $\mathrm{Br}$ f Haematol 1978;40:609-15.

2 Gaffney PJ, Perry MJ. Unreliability of current serum fibrin degradation product (FDP) assays. Thromb Haemost 1985; 53:301-2.

3 Greenberg CS, Devine DV, McCree KM. Measurement of plasma fibrin D-dimer levels with the use of a monoclonal antibody coupled to latex beads. Am f Clin Pathol 1987; 87:94-100.

4 Elms JM, Bunce IH, Bundesen PG, et al. Rapid detection of cross-linked fibrin degradation products in plasma using monoclonal antibody-coated latex particles. Am f Clin Pathol 1986;85:360-4.

5 Ballegeer V, Mombaerts P, Declecrek PJ, Spitz B, VonAssche FA, Collen D. Fibrinolytic response to venous VonAssche FA, Collen D. Fibrinolytic response to venous
occlusion and fibrin fragment D-dimer levels in normal and complicated pregnancy. Thromb Haemost 1987; 58:1030-2

6 Stiehm, Clantanoft. Split products of fibrin in the serum of newborns. Pediatrics 1969;43:770-80.

\section{St Mary's Hospital, Manchester T Mohammed M Maresh C P Sibley R D H Boyd \\ Correspondence to: Dr T Mohammed, Department of Child Health, Research Floor, Manchester M13 0JH.}

Accepted 7 September 1989

\title{
Absent maternofetal potassium gradient at term
}

\author{
T Mohammed, M Maresh, C P Sibley, R D H Boyd
}

\begin{abstract}
Mean (SE) umbilical venous plasma potassium concentrations at $5 \cdot 5,10,20$, and 30 minutes after the start of laparotomy at term were $4.75(0.15), 5.95(0.26), 6.81(0.23)$, and $7.59(0.81) \mathrm{mmol} / \mathrm{kg}$ plasma water. Maternal peripheral venous plasma concentrations were $4 \cdot 30(0 \cdot 13)$ before and $4 \cdot 26(0 \cdot 23)$ $\mathrm{mmol} / \mathrm{kg}$ plasma water after laparotomy. Plasma calcium concentration in maternal and cord blood did not change significantly.
\end{abstract}

A reported higher umbilical than maternal venous plasma concentration of potassium at full term in the human ${ }^{12}$ has been taken as prima facie evidence that the ion is actively transported across human placenta. ${ }^{3}$ We have reinvestigated the human maternofetal venous plasma gradient reported with particular attention to time of sampling and find that, as in the rat, ${ }^{4}$ the umbilical plasma concentration rises immediately after delivery. It appears that the reported concentration difference is likely to be artefactual.

\section{Subjects and methods}

After ethical approval and maternal consent, 19 pregnant women undergoing elective caesarean section for previous section were selected on days that were convenient for study. A maternal peripheral venous blood sample of about 5 to $10 \mathrm{ml}$, from a large vein usually in the antecubital fossa using a 21 gauge needle, was taken when the patient entered the anaesthetic room about 30 minutes before surgery. A further maternal sample was taken at the end of the operation about 60 minutes after the first.

Timing of umbilical sampling was related to 